\title{
German Cockroach Antigen IgG Antibody Measurement
}

National Cancer Institute

\section{Source}

National Cancer Institute. German Cockroach Antigen Ig G Antibody Measurement. NCI

Thesaurus. Code C130142.

A measurement of the German cockroach (Blattella germanica) antigen IgG antibody in a biological specimen. 